Онлайн-доступ к журналу: http://journal.iro38.ru

УДК $811.161 .1+81.243+37.012$

Использование результатов диагностического анкетирования монгольских студентов в решении проблем преподавания русского языка как иностранного в иноязычной образовательной среде

Н. П. Хинзеева

Улан-Баторский филиал Российского экономического университета им. Г. В. Плеханова, Монголия, г. Улан-Батор

Аннотация. Введение. Статья посвящена проблемам изучения русского языка как иностранного и обучения ему. Целью работы является выявление и анализ проблем в преподавании русского языка как иностранного, изучение причин, препятствуюших адекватному усвоению языка и выделение основных факторов, способствуюших эффрективному обучению русскому языку как иностранному.

Материалы и методы. В процессе обобщения фактического материала автором была выявлена научная новизна, которая состоит во внедрении коучинговых технологий в методику преподавания русского языка как иностранного. Реализация этой технологии связана с системно-деятельностным и практико-ориентированным подходами к обучению иностранных студентов. Теоретическая значимость работы заключается в определении стратегической конщепции: «профессиональный коммуникатор (преподаватель) - коуч (студент)», которая заключается в том, что деятельность коммуникатора связана с воздействием на партнёра, его мировоззрение, систему изенностей, его поведение и реализуется с помощьюю коммуникативных стратегий и тактик: прагматических, диалоговых, риторических, а взаимодействие коуча происходит благодаря диалоговой, недирективной политике, субъект-субъектному характеру деятельности.

Результаты исследования. Результать исследования, представленные в статье, теоретически и практически значимы для совершенствования методики преподавания русского языка как иностранного. Приводятся рекомендащии по решению поднятых проблем, и делается вывод 


\section{Ключевые}

слова:

\section{Для}

цитирования:

Дата поступления статьи в редакцию: 18 февраля 2020 г. о том, что системно-деятельностный и практико-ориентированный подходы должны работать в комплексе и быть одними из ведущих в обучении.

Заключение. Практическая значимость исследования состоит в его направленности на совершенствование коммуникативной компетенции иностранного студента. Перспективность данного направления в науке определяется необходимостью совершенствования коммуникативной компетентности у иностранного студента; дальнейшего исследования требует изучение новых методов и форм преподавания русского языка как иностранного.

проблемы в изучении русского языка как иностранного, системно-деятельностный и практико-ориентированный подходы, профессиональный коммуникатор, коуч, коммуникативное взаимодействие.

Хинзеева Н. П. Использование результатов диагностического анкетирования монгольских студентов в решении проблем преподавания русского языка как иностранного в иноязычной образовательной среде // Педагогический ИМИДЖ. 2020. Т. 14. № 2 (47).

C. $113-132$.

DOI: $10.32343 / 2409-5052-2020-14-2-113-132$

\section{Введение}

Изучение любого иностранного языка сопровождается различными факторами, которые влияют на процесс его изучения в целом. Это и желание самого человека, и его индивидуально-психологические особенности, и уровень языковой подготовки, благоприятная психологическая обстановка, роль преподавателя в учебном процессе и т. д. Все эти факторы определяют проблемы, с которыми сталкивается практически каждый преподаватель иностранных языков и которые требуют определённого алгоритма их решений.

Преподаватель должен решить основную задачу - дать студентам необходимые знания по определённому предмету и сформировать навыки и умения использования этих знаний в практической деятельности [6. с. 1], иначе говоря, сформировать профессиональную компетентность. Перед преподавателем русского языка как иностранного также стоит непростая задача - сформировать у иностранных студентов языковые, речевые компетенции и перевести навыки использования данных компетенций в практическую плоскость. 
Учёные - исследователи в области русского как иностранного: Т. М. Балыхина, И. М. Логинова, К. В. Маёрова, О. И. Руденко-Моргун, С. А. Хавронина, В. М. Шаклеин, Д. Б. Гудков, С. Г. Тер-Минасова, А. Н. Щукин, И. П. Лысакова, В. Г. Костомаров, О. Д. Митрофанова, Л. Н. Анипкина и др. - рассматривают различные аспекты методики преподавания русского языка как иностранного (РКИ) и особенности его изучения иностранными студентами. Так, учёные в области методики преподавания РКИ сходятся во мнении, что формирование и развитие коммуникативной компетенции и коммуникативной компетентности является основой для успешного обучения на иностранном языке.

Мы придерживаемся мнения С. Г. Тер-Минасовой, которая в своём исследовании о языке и межкультурной коммуникации говорит о том, что коммуникативная компетенция, обретённая в период изучения иностранного языка, является способностью и готовностью студентов использовать иностранный язык в разных ситуациях общения, а также при работе с иноязычной информацией; способностью вести диалог культур, поскольку «каждый урок иностранного языка - это перекрёсток культур, это практика межкультурной коммуникации, потому что каждое иностранное слово отражает иностранный мир и иностранную культуру: за каждым словом стоит обусловленное национальным сознанием представление о мире» [10, с. 24].

Особую трудность вызывает ситуация родной среды студента в условиях иноязычного образования, в котором оказались студенты Улан-Баторского филиала РЭУ им. Г. В. Плеханова. Проблема изучения русского языка в условиях родной среды иностранца назрела достаточно давно и остаётся актуальной до сих пор, поскольку, находясь в родной среде, студенты вовлечены в другой, инокультурный, иноязычный процесс обучения.

В методике РКИ принято выделять следующие цели обучения: практическую, образовательную, воспитательную. Для достижения этих целей необходимо решить множество задач, которые начинаются от постановки звуков русского алфавита до продуктивной, грамотной речи на русском языке. Это возможно, по нашему мнению, при использовании эффективных, на наш взгляд, подходов в обучении.

В научной литературе понятие «подход» понимается как совокупность принципов, методов, способствующих решению проблемы. Одним из распространённых подходов к исследованию и организации образовательного процесса является системно-деятельностный, включающий в себя два понятия: «система» и «деятельность».

Системный подход разрабатывался в исследованиях классиков отечественной науки, таких как Б. Г. Ананьев, Б. Ф. Ломов и др. В педагогике существуют различные подходы использования общей теории систем к анализу педагогической деятельности. Методологические исследования А. Н. Аверьянова, В. И. Загвязинского, В. В. Краевского, В. А. Сластенина и др. обосновывают целесообразность применения общей теории систем и системного анализа в педагогике [1, с. 25].

В отечественной науке в системно-деятельностном подходе категория «деятельность» занимает одно из ключевых мест, а деятельность сама рассматривается как своего рода система, как преднамеренная активность человека, проявляемая в процессе его взаимодействия с окружающим миром, и это вза- 
имодействие заключается в решении жизненно важных задач, определяющих существование и развитие человека. Системно-деятельностный подход обеспечивает достижение планируемых результатов освоения основной образовательной программы вуза и создаёт основу для самостоятельного успешного усвоения обучающимися новых знаний, умений, компетенций, видов и способов деятельности. Применение данного подхода создаёт благоприятные условия для разноуровневой подготовки учащихся, реализации принципа моделирования, поскольку направлен на развитие каждого обучающегося, на формирование его индивидуальных способностей.

Таким образом, системно-деятельностный подход выступает как разработанная последовательность деятельностных шагов. Считаем необходимым рассмотреть образовательную среду вуза как систему, в которой формируется профессиональная компетентность.

Методологическим аспектом удовлетворения потребности в профессиональном становлении студентов является практико-ориентированный подход в обучении. Несомненно, создание практико-ориентированной образовательной среды и её влияние на становление, развитие и самосовершенствование личности остаётся актуальной проблемой педагогики. В практико-ориентированном подходе обучения специалистов, по мнению учёных, существует три подхода, которые различаются следующими характеристиками:

- первый и наиболее узкий подход связывает практико-ориентированное обучение с формированием профессионального опыта студентов при погружении их в профессиональную среду в ходе учебной, производственной и преддипломной практики (Ю. Ветров, Н. Клушина);

- второй подход (авторы Т. Дмитриенко, П. Образцов) при практико-ориентированном обучении предполагает использование профессионально-ориентированных технологий обучения и методик моделирования фрагментов будущей профессиональной деятельности на основе использования возможностей контекстного (профессионально направленного) изучения профильных и непрофильных дисциплин;

- третий, наиболее широкий подход, очень ёмко сформулировал Ф. Г. Ялалов в деятельностно-компетентностной парадигме, в соответствии с которой практико-ориентированное образование направлено на приобретение кроме знаний, умений, навыков опыта практической деятельности с целью достижения профессионально и социально значимых компетентностей. Это обеспечивает вовлечение студентов в работу и их активность, сравнимую с активностью преподавателя. Мотивация к изучению теоретического материала идёт от потребности в решении практической задачи.

Практико-ориентированный подход к обучению в образовательном учреждении должен способствовать поэтапному формированию профессиональных компетенций личности студента. Всего существует четыре этапа. Рассмотрим их подробнее.

1 этап - смысловой. На данном этапе происходит адаптация к образовательному пространству: у студентов формируются культурные запросы и потребности, понимание сущности и социальной значимости своей будущей профессии, проявление к ней устойчивого интереса.

2 этап - ценностный. Начинается специализация, в которой происходит 
укрепление и углубление профессиональных интересов студентов, а также формируется самостоятельность в определении задач профессионального и личностного развития. Студенты не просто закрепляют основные теоретические положения учебного материала, но и учатся прогнозировать, планировать, раскрывать свою точку зрения в диалоге, самостоятельно организовывать свою деятельность.

3 этап - практический. Непосредственное знакомство с профессиональной деятельностью в период освоения профессиональных модулей и прохождения учебной практики, готовность к дифференцированной оценке уровня своего профессионализма и активность позиции. В период освоения учебных дисциплин/междисциплинарных курсов студенты разрабатывают проекты в малых группах по 5-6 человек, где в основу работы положен диалог. Диалог является средством выявления проблемы и путей её решения. На этом этапе выполняется полный цикл исследовательской деятельности: от изучения предметной области и выделения проблемы до её реализации. Результатом учебной практики является разработанный под руководством специалистов программный продукт для решения небольших по объёму задач, выбранных из круга актуальных проблем. Кроме практической работы будущие специалисты знакомятся с реальными задачами производства, их постановкой, решением, документированием и презентацией.

4 этап - заключительный. Готовность организовывать собственную деятельность, выбирать типовые методы и способы выполнения профессиональных задач, оценивать их эффективность и качество. К заключительному этапу обучения относятся производственная практика по виду профессиональной деятельности, сдача экзамена (квалификационного) по профессиональному модулю; преддипломная практика и защита дипломного проекта (работы) [4, c. 2-4].

Таким образом, в иноязычной образовательной среде вуза при обучении иностранному языку мы предлагаем применять системно-деятельностный и практико-ориентированный подходы в комплексе, поскольку деятельность всегда активна и выражается в исключительно практической направленности.

В соответствии с этим нами было проведено заседание круглого стола, на котором обсуждались актуальные проблемы изучения русского языка и пути их решения. Целью работы является выявление и анализ проблем в преподавании русского языка как иностранного, изучение причин, препятствующих адекватному усвоению языка и выделение основных факторов, способствующих эффективному обучению русскому языку как иностранному.

В процессе обобщения фактического материала нами была выявлена научная новизна, которая состоит во внедрении коучинговых технологий в методику преподавания РКИ. Реализация этой технологии связана с системно-деятельностным и практико-ориентированным подходами к обучению иностранных студентов. Теоретическая значимость исследования заключается в определении стратегической концепции субъект-субъектной деятельности: «профессиональный коммуникатор (преподаватель) - коуч (студент)». Результаты исследования, представленные в статье, теоретически и практически значимы для совершенствования методики преподавания РКИ. 
Среди студентов был проведён опросник «Проблемы в изучении русского языка», состоящий из четырнадцати вопросов. В опроснике приняли участие 57 иностранных студентов 1-3 курсов. Нами использовались следующие методы исследования: теоретические (анализ, синтез, обобщение и систематизация полученного материала); эмпирические (констатирующие данные, количественный и качественный анализ результатов исследования); статистические методы вторичной обработки полученных данных (группировка, табличная и диаграммная интерпретация данных, сопоставительный анализ экспериментальных данных).

Начало изучения русского языка

Диаграмма 1

Diagram 1

Start of learning the Russian language

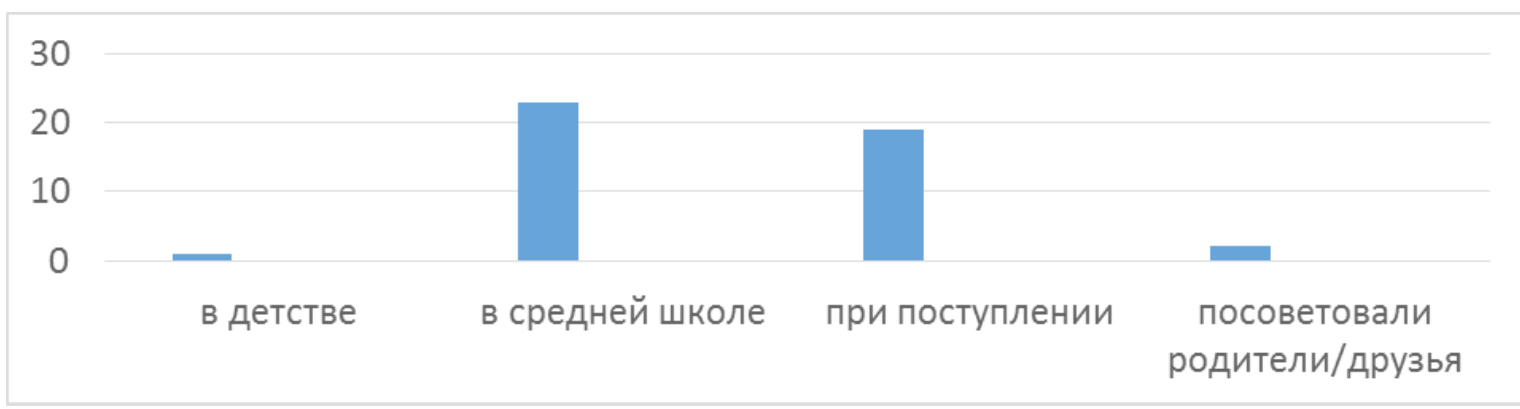

Итак, на первый вопрос опросника: «Когда Вы решили изучать русский язык» - студенты ответили таким образом... (ответ изложен в диграмме 1).

Итак, по данным первого опроса было выявлено, что большинство студентов определились с выбором иностранного языка ещё в школе, и можно предположить, что они достаточно мотивированы. Так ли это на самом деле, нам покажет следующая диаграмма (диаграмма 2), в которой показаны ответы на второй вопрос: «Почему Вы решили изучать русский язык?»

Диаграмма 2

Причины изучения

Diagram 2

Reasons for learning

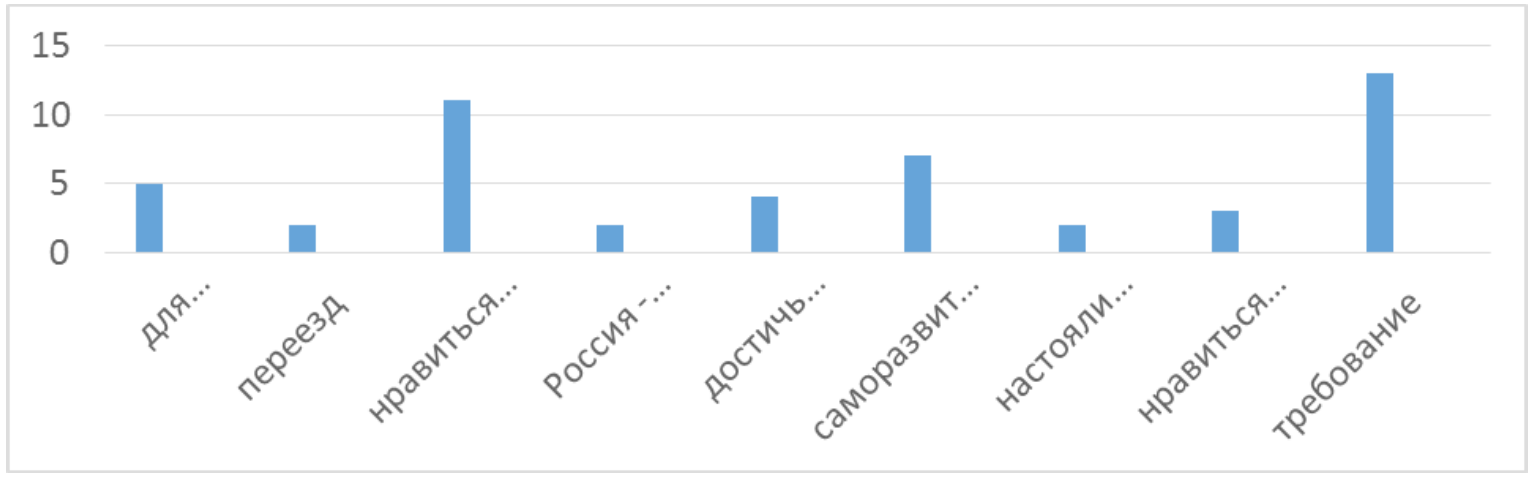


Как видно из диаграммы 2, наибольший процент ответов на этот вопрос указывает на то, что знание языка - это, прежде всего, требование, без которого невозможно учиться в иностранном вузе. При последующем анализе проблемы было выявлено, что многие студенты вовсе и не были заинтересованы в изучении русского языка, а изучают его, так как это «надо/ нужно», «все предметы на русском языке» и т. д. Эти данные показывают, что более половины опрошенных студентов учатся не потому, что им интересно, а потому, что знать русский язык нужно для учёбы в университете. Студенты предлагают больше проводить внеучебных мероприятий, тематических вечеров; готовить различного рода декады и т. д. Стоит заметить, что воспитательная работа в филиале достаточно проработана и насыщена различными мероприятиями. Однако обсуждение за круглым столом свидетельствует о том, что студентам нравится принимать участие во внеучебной деятельности университета, они готовы активно взаимодействовать как друг с другом, так и с другими участниками учебного процесса: преподавателями, студентами - носителями языка и др. Внеучебные мероприятия способствуют развитию спонтанной, неподготовленной речи, поскольку такая речь заставляет студента выражать свои мысли в зависимости от возникающей ситуации и быстро реагировать на происходящие изменения, при которых студенту необходимо использовать накопленный запас знаний, умений и навыков для её разрешения [1, с. 87].

Кроме основной причины, которую назвали студенты, есть и другие, указывающие на мотивацию в целом. Это и причины эмпатии к языку, саморазвития, дальнейшей профессиональной деятельности, достижения своей определённой цели и т. д.

Таким образом, действительно существует проблема недостаточной мотивированности студентов в изучении языка, которую возможно решить при увеличении и усилении внеучебных мероприятий, поскольку студенты, находясь в родной среде, испытывают дефицит общения на русском языке.

Ещё одним важным моментом в обсуждении стало то, что многим студентам трудно воспринимать грамматику русского языка. Изучение любого иностранного языка неразрывно связано с грамматикой, поскольку без знания основных фоновых знаний невозможно правильно и грамотно коммуницировать на языке. Поэтому грамматика, с одной стороны, как необходимый элемент в обучении, является основой изучения языка, с другой стороны, выступает неким сдерживающим фактором. Так, на следующий вопрос о самой трудной теме русского языка были даны такие ответы (диаграмма 3).

Итак, исходя из этой диаграммы, мы можем сделать вывод о том, что превалирующее большинство студентов испытывают трудности при прохождении таких тем, как «Причастие», «Деепричастие» и др. Усвоение и закрепление данных тем, конечно же,

Трудные темы русского языка

Диаграмла 3

Diagram 3

\section{Difficult topics of the Russian language}

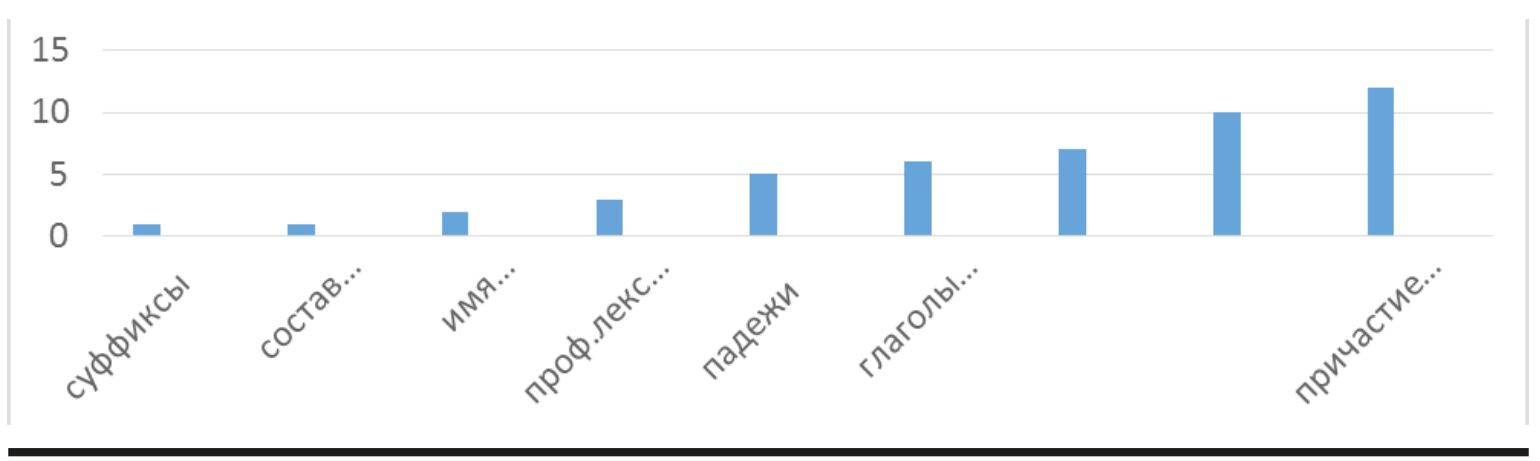


должно проходить после изучения определённого пласта грамматики. Работу над наиболее сложными темами следует проводить в комплексе, опираясь либо на текстовый материал, либо на разработанные задания по теме. Одним из эффективных решений данной проблемы, по нашему мнению, является работа над текстом, в основе которого лежат коммуникативные и речевые стереотипы, отражающие действительность. Отобранный материал текста должен отличаться новизной, доступностью формы, оригинальным, креативным изложением, небольшим объёмом, познавательным и событийным характером изложения. Такого рода тексты решают не только воспитательные, познавательные задачи, но и выполняют функции тренажёра, благодаря чему отрабатываются определённые грамматические и лексические формы [1, с. 81-82].

Многофункциональность и многозадачность такого средства обучения, как текст, способствует решению многих задач: знакомство с новой лексикой; работа над чтением, говорением, иногда и письмом; отработка грамматических конструкций и т. д. Главное преимущество использования текста, на наш взгляд, состоит в том, что, работая над текстом, студент может применить полученную информацию на практике, употребив в своей речи грамматический инструментарий. Часть опрошенных студентов считает, что грамматика русского языка трудная и нет лёгких тем в русском языке. В данном случае необходимо опровергать такие умозаключения, поскольку сложность в достижении цели (в большинстве случаев надуманная) является весомой преградой в осуществлении поставленной цели - изучения языка. Мы считаем, что использование системно-деятельностного подхода в обучении сможет разрешить данную проблему. Применение данного подхода создаёт благоприятные условия для разноуровневой подготовки учащихся, реализации принципа моделирования, поскольку направлен на развитие каждого обучающегося, на формирование его индивидуальных способностей $[1$, c. 26]. Поэтому системность и методичность в преподавании играет значительную роль в усвоении определённых знаний, приобретении умений и навыков. Таким образом, проблемы усвоения грамматики, с нашей точки зрения, целесообразно решать в комплексе мер, которые предусматривают системный и многофункциональный подход.

Если наиболее трудные темы грамматики русского языка решаются посредством определённых задач, то наиболее лёгкие темы, по мнению студентов, способствуют успешности обучения, поскольку понимание и усвоение таких тем формирует и развивает полученные навыки. Так, исходя из диаграммы 4, мы можем сделать вывод о том, что многим студентам легко воспринимать тему о категории рода и числа. Треть студентов полагает, что падежи русского языка не представляют трудности в изучении. Данные категории являются основополагающими категориями грамматики русского языка, и отрадно отметить, что студенты понимают важность изучения этих категорий. Однако есть такие студенты, которые считают, что русский язык достаточно сложный,

Диаграмма 4

Лёгкие темы русского языка

Diagram 4

Easy topics of the Russian language

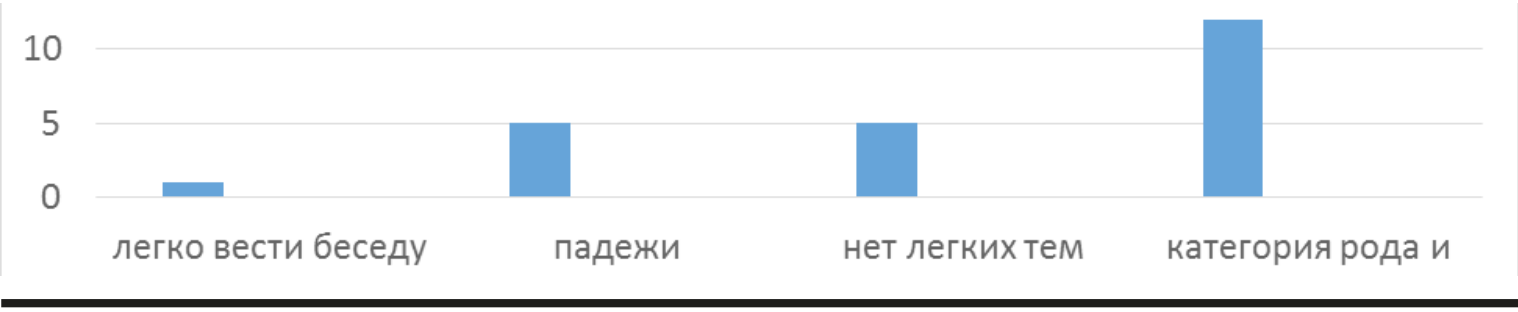


и, собственно говоря, нет лёгких тем (диаграмма 4).

Следующий вопрос был задан в позитивно окрашенной форме: «Что, по вашему мнению, легко Вам даётся?». Исходя из специфики предыдущего вопроса и стереотипа о том, что русский язык достаточно сложный язык для изучения, мы намеренно воспользовались такой формулировкой для того, чтобы студент мог для себя чётко определить, что ему легче или сложнее изучать. Этот вопрос включал в себя четыре пункта, поделённый соответственно на четыре вида речевой деятельности: письмо, чтение, аудирование, говорение. Рассмотрим их подробнее.

По виду речевой деятельности «Письмо» были даны следующие ответы (диаграмма 5).

Диаграмма 5

Письмо

Diagram 5

Writing

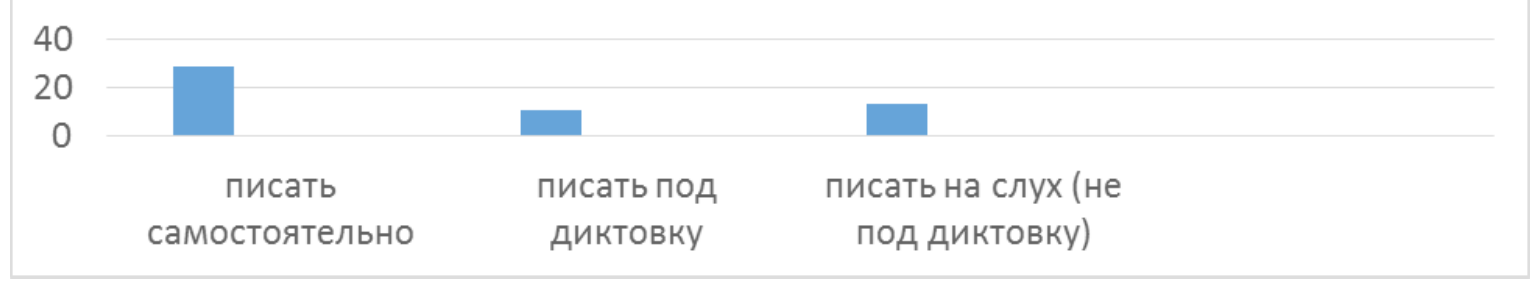

Превалирующему большинству студентов нравится писать самостоятельно. Это и закономерно, поскольку при написании можно самостоятельно строить предложения, возвращаться к уже написанному, корректировать, исправлять, дополнять, убирать лишнее и т. д. Как оказалось, писать под диктовку студентам значительно сложнее, и в этом состоит ещё одна проблема в изучении русского языка. При решении данной проблемы нами была определена стратегия, по которой был предложен проект лекционных занятий и диктантов по русскому языку: темп и тон речи преподавателя должны варьироваться от быстрого до медленного/громкого/тихого; требуется написание на слух труднопроизносимых, сложных слов и выражений и т. д. Тематика диктантов должна соответствовать так называемым профессиональным темам для узнавания, понимания и запоминания профессиональной терминологии.

На вопрос: «Легко ли вам читать по-русски?»- студенты ответили, что читать и пересказывать им легче и интереснее, чем читать и писать о прочитанном. Если вернуться к анализу предыдущего вопроса, то при определении письма как вида речевой деятельности студенты указывали, что писать самостоятельно им намного проще. Однако оказалось, что писать о прочитанном им значительно труднее. Данный факт говорит о том, что студентам проще воспроизвести полученную информацию из текста посредством устной речи, используя жестикуляцию и мимику. Писать о прочитанном, вернее, излагать чужую речь на письме - достаточно трудоёмкий процесс, в котором нужно 
Чтение

\section{Reading}

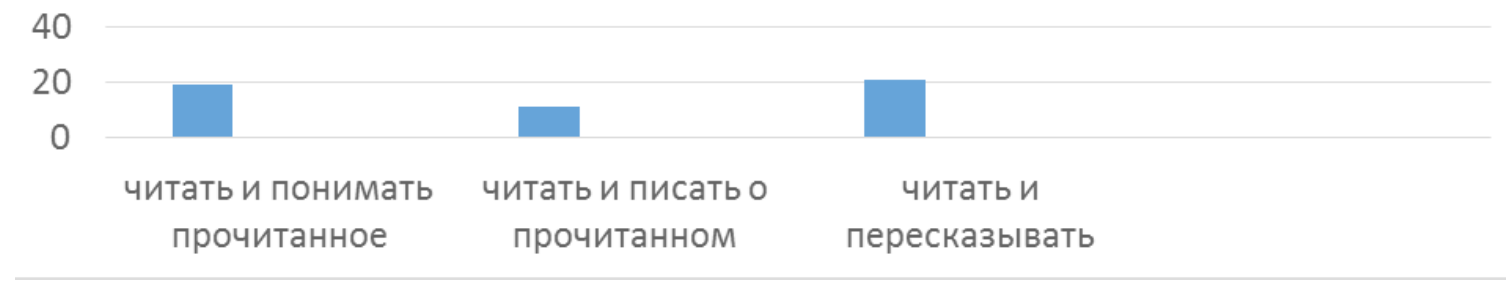

учитывать стиль повествования автора, детали и структуру текста (диаграмма 6).

Для решения вышеизложенной проблемы рекомендуется использование метода трёх «П»: практика - практика - практика. Иначе говоря, нужно больше практиковать в учебной деятельности метод конспектирования, изложения, реферирования с требованиями оформления научных работ и их дальнейшей презентацией и защитой. Такая работа, несомненно, будет способствовать развитию грамотного письма и улучшению навыков устной речи, а также грамотному оформлению различных научных работ, документов и писем.

Следующий вопрос об аудировании дал такие результаты. Большинство студентов ответили, что «слушать и говорить» им легче и удобнее, чем слушать аудиовидеозаписи, а потом услышанное и увиденное воспроизводить в режиме онлайн. В ситуациях реального общения собеседникам лучше ориентироваться в потоке информации, поскольку диалогичность всегда имеет преимущества: есть возможность уточнить информацию, переспросить, ответить позже и т. д. Искусственность и регламентированность записанных файлов аудиовидеозаписей не позволяет отходить от принятого содержания и диктует свои условия. Слушать и понимать собеседника студентам немного тяжелее, чем слушать и говорить. В ситуациях говорения у коммуниканта есть несколько приёмов, которые он может использовать при разговоре, а процесс понимания и переработки информации трудоёмок, так как происходит сложная мыслительная деятельность по переводу иностранной речи на родную, а затем преводу репродуктивной речи в продуктивную. Некоторым студентам «слушать и писать» труднее, поскольку им нужно передать именно ту информацию, которую они услышали (диаграмма 7).

Диаграмма 7

Аудирование

Diagram 7

Listening

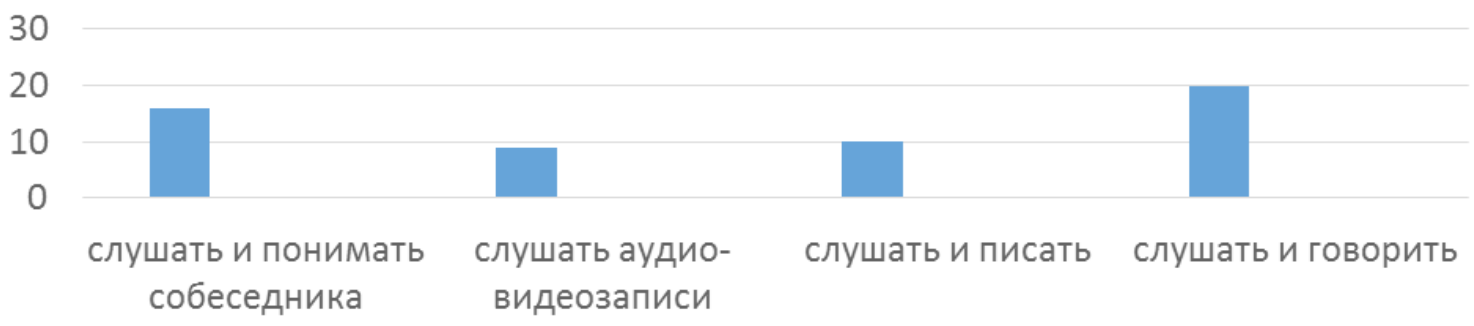


Таким образом, из анализа видно, что студенты предпочитают больше слушать и говорить друг с другом и меньше реагируют на записанные материалы. Решение данной проблемы представляется возможным при использовании разнообразных методов, например, в различной подаче использования аудиовидеозаписей с заданиями на скорость понимания информации, на реакцию слушателя и т. д.

Последним из серии вопросов: «Что, по Вашему мнению, легко Вам даётся?» - был вопрос о таком виде речевой деятельности, как говорение. Наибольший процент голосов набрал пункт «говорить друг с другом». Студентам нравится разговаривать друг с другом, вести беседы в непринужденной атмосфере общения. На занятиях по русскому языку студентам предлагаются задания с коммуникативной направленностью: различные ситуации общения; кейс-стади, решение возникающих проблем при коммуникации; моделирование неожиданных ситуаций, их спонтанность и др. Например, такие предложенные темы, как «Неожиданная встреча старых знакомых», «Помогите человеку» (в различных ситуациях), «Разговор в банке» и т. д., реалистичны и поэтому эффективны, поскольку в таких ситуациях вырабатывается стихийность речи (диаграмма 8).

Диаграмма 8

Говорение

Diagram 8

Speaking

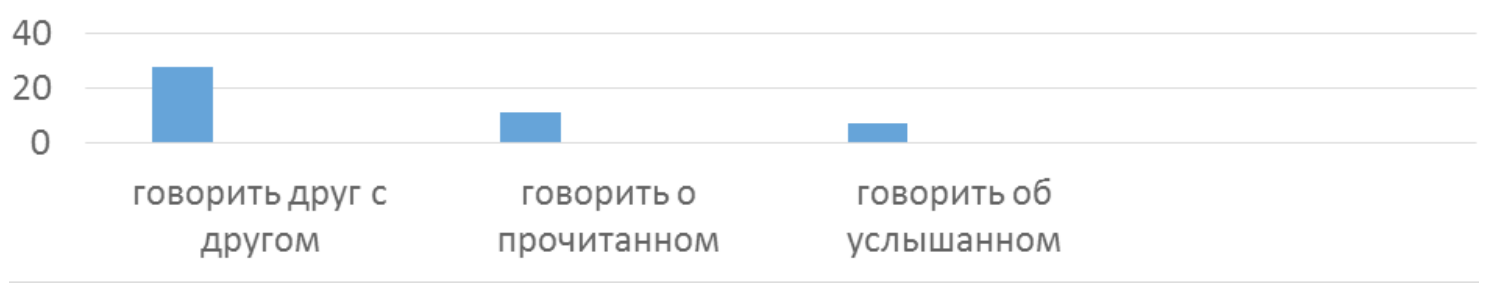

Следующие вопросы к студентам звучали так: «Какие темы Вам интересны?», «О чём Вы разговариваете, каковы Ваши предпочтения в общении?» (диаграмма 9).

Диаграмла 9

Любимые темы для обсуждений

Diagram 9

Favorite topics for discussions

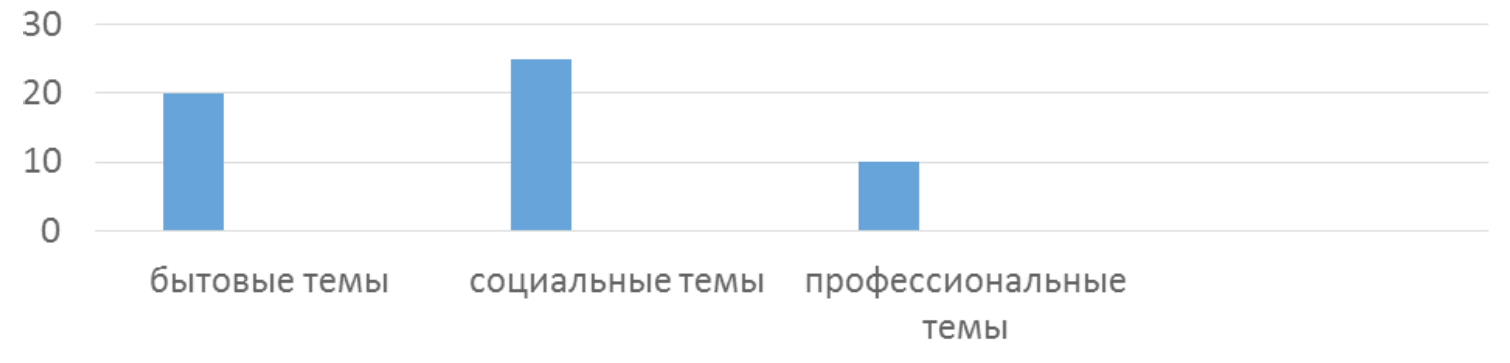


Как видно из графика, наибольшее количество студентов ответили, что социальные темы их волнуют больше, чем профессиональные. Это можно объяснить тем, что у студентов есть потребность в обсуждении социальных проблем, так как они сами непосредственно участвуют в общественной жизни и понимают, с какими проблемами может столкнуться человек в социуме. Поэтому проблемы в жизни и в обществе весьма актуальны и требуют определённых решений.

Профессиональная тематика сложна и необходима тем, что студент-выпускник-специалист в своей профессиональной деятельности должен уметь пользоваться профессиональной терминологией и владеть ею в профессиональных целях. Иначе говоря, у студента к окончанию университета должна быть сформирована коммуникативная компетентность, которая является одной из основных и важных свойств личности выпускника. И. И. Барахович в своей статье «Коммуникация педагога: дидактический аспект» пишет: «Выпускник современной образовательной организации должен обладать навыками межотраслевой коммуникации, умением управлять проектами и процессами, умением работать в группах, коллективах, командах и с отдельными партнёрами, умением быстро принимать решения, ориентироваться на запросы партнёра по взаимодействию, реагировать на изменение условий и регулировать своё поведение и поведение партнёров» [2, с. 86]. Поэтому для достижения этой цели необходимо, на наш взгляд, использовать технологию проектного моделирования ситуаций и технику проблемного метода. Также эффективным с точки зрения формирования компетентности будет применение опыта научно-исследовательской работы. Так, при прохождении новой темы «Немного о налогах» целесообразным будет применение на занятиях модели диалога «Налоговый консультант - Клиент», в рамках которого будет использована лексика, предварительно изученная на предыдущих занятиях. Немаловажным аспектом в изучении данной темы будет применение аутентичных текстов с творческими заданиями, предъявляемых в научных журналах. Традиционное выполнение заданий по написанию докладов и эссе, презентаций и выступлений также сыграет важную роль в формировании коммуникативной компетентности. Однако нужно помнить о том, что данные виды работ должны быть с интерактивными творческими заданиями, интересными для студентов. Так, при защите докладов нужно остерегаться механического приёма - чтения текста. Например, доклад о фондовой бирже можно представить в виде презентаций или в виде работы-коучинга как совокупности методов, направленных на решение конкретных проблем и задач путём образовательных лекций, тренингов и диалога. Коуч-студент должен направлять, разъяснять, учить, открывать лучшие стороны характера и непоколебимо верить в успех клиента [3; 5].

Таким образом, работа по формированию коммуникативной компетентности должна быть направлена, прежде всего, на развитие творческого потенциала студентов путём применения достаточно традиционных на сегодняшний день интерактивных технологий.

Следующий вопрос был озвучен таким образом: «Трудно ли Вам переводить?» Превалирующее большинство студентов ответили, что переводить им трудно. Данный вид работы трудоёмок, поскольку перевод - текст, переведённый с одного языка на другой [8], представляет собой сложный мыслительный процесс перевода чужой речи на родную речь и наоборот (диаграмма 10). 
Диаграмма 10

Трудности перевода

Difficulties of translation

Diagram 10

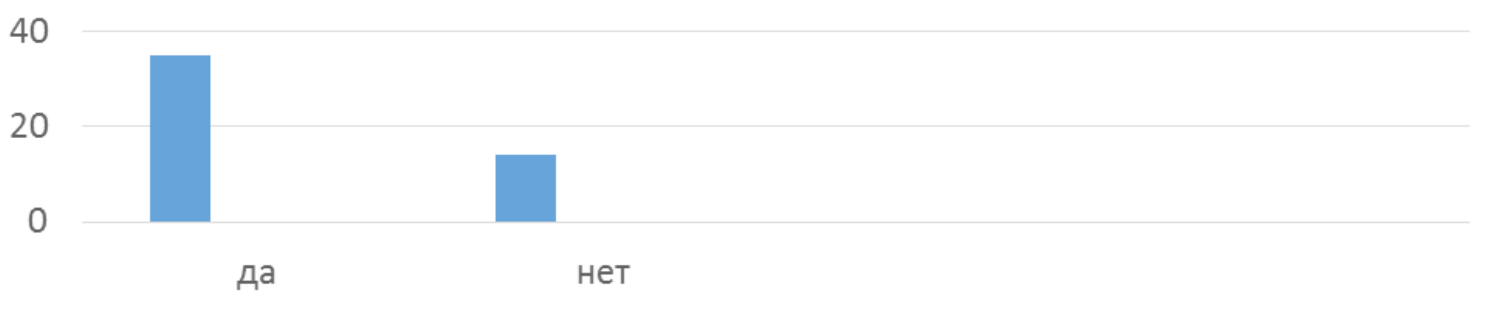

Ответы на вопрос: «Если переводить, то лучше переводить: а) с русского языка на родной; б) с родного языка на русский?» - отражены в диаграмме 11.

Диаграмма 11

Языковые особенности перевода

Diagram 11

Linguistic features of translation

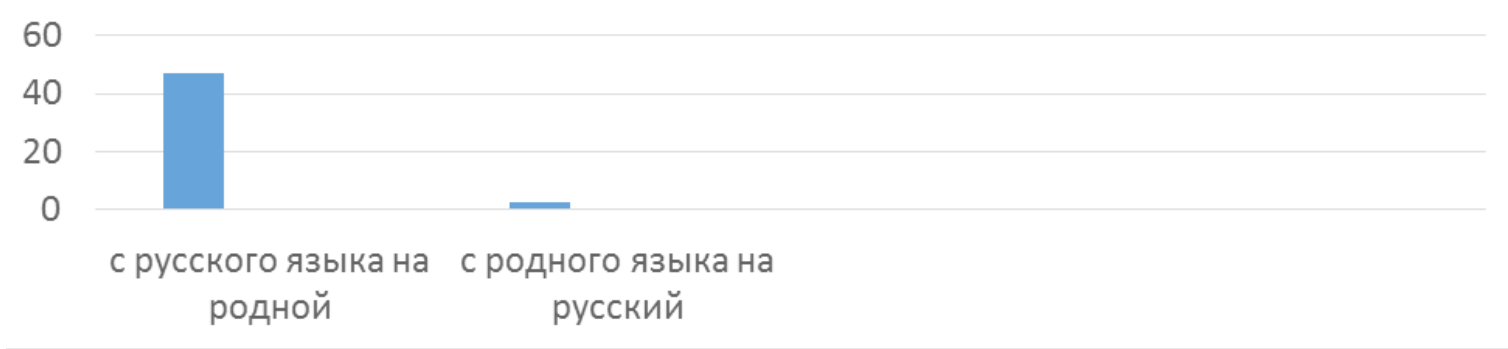

Из графика видно, что студентам лучше письменно переводить иноязычный (русский) текст, нежели переводить с родного языка на русский. Этот факт объясняется тем, что перевод на родную речь имеет свои особенности. С одной стороны, будучи носителем языка, переводчик сможет стилистически более грамотно предоставить информацию на родном языке. Только носитель языка может идентифицировать сложные для восприятия логические конструкции, адекватно разъяснить реалии, интуитивно подобрать наиболее удачные стилистические приёмы [9]. Однако, с другой стороны, если переводчику предстоит устный разговор с потенциальным носителем другого языка, то будет достаточно трудно определить общую картину взаимосвязей, поэтому перевод может исказиться в фонетическом, лексическом, синтаксическом плане.

Другую картину представляет перевод с родного языка на русский. Переводчику достаточно сложно перевести стилистические конструкции с родного языка на другой, так как ему необходимо идентифицировать их на предмет адекватности восприятия и логической взаимосвязи. Для решения этой проблемы на занятиях по русскому языку студентам предлагаются задания на сравнительно-сопоставительный метод перевода, в котором тексты должны быть, по нашему мнению, короткими и обязательно содержательными с точки зрения обучения, познания и воспитания. 
Двойной перевод - это весьма эффективный метод в изучении иностранного языка. Например, оригинальный текст на русском языке студенты сначала переводят на свой родной язык, затем этот же свой переведённый текст с родного языка снова переводят в оригинал. Получается два разных текста: оригинальный текст на русском языке и переведённый студентом текст на русском языке. Такой вид перевода имеет ряд преимуществ: во-первых, происходит сравнительно-сопоставительный анализ текстов, на основе которого существенным образом пополняется словарный запас, отрабатываются грамматические, стилистические конструкции языка и т. д.; во-вторых, переводимые тексты, предлагаемые преподавателем, несут познавательную, и, самое главное, воспитательную функцию. Например, в этом тексте нужно использовать сравнительно-сопоставительный метод перевода: «Уничтожение любой нации не требует использования атомных бомб или использования ракет дальнего радиуса действия. Требуется только снижение качества образования и разрешение обмана на экзаменах учащимися. Пациенты умирают от рук таких врачей. Здания разрушаются от рук таких инженеров. Деньги теряются от рук таких экономистов и бухгалтеров. Человечество умирает от рук таких религиозных учёных. Справедливость утрачивается от рук таких юристов и судей. Управление теряется в руках законодателей. Крах образования - это крах нации!»

Таким образом, мы видим, что иноязычный функциональный текст можно перевести на родной язык более свободно, при переводе носитель языка может использовать аналогичные конструкции своего родного языка, заменить иностранные слова тождественными и т. д. Перевод представляет собой вид языкового посредничества, который выступает в качестве полноценной коммуникативной замены оригинала [7] и средством к изучению языка.

На вопрос: «Нужно ли использовать родной язык на занятиях по русскому языку?» - наибольшее количество студентов ответили утвердительно. По нашему мнению, применение сознательного принципа в обучении и использование родного языка при изучении теоретических аспектов языка благоприятно скажется на иноязычном учебном процессе, поскольку студенты должны осознанно подходить к процессу обучения. Осознанное и осмысленное отношение к учёбе способствует, в первую очередь, развитию мотивации, эффективному восприятию материала, пониманию сложных грамматических тем.

Диаграмма 12

Использование родного языка

Diagram 12

The use of mother tongue

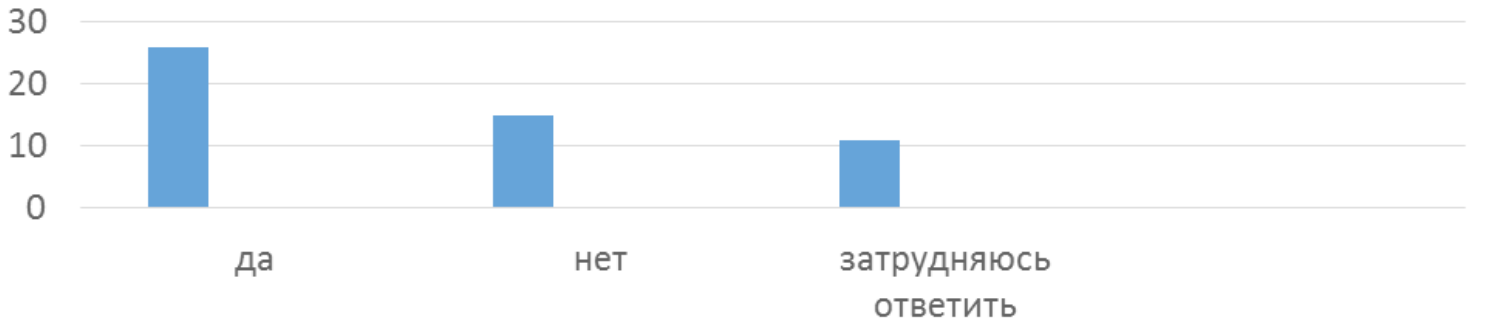


Исходя из вышеизложенного (диаграмма 12) мы можем сказать, что родной язык способствует эффективному изучению иностранного языка и обучению ему, а также позитивному отношению студента к учебному процессу в целом.

Пожелания и замечания студентов к проведению занятий по русскому языку были следующими (диаграмма 13).

Диаграмма 13

Пожелания/замечания студентов

Wishes/remarks of students

Diagram 13

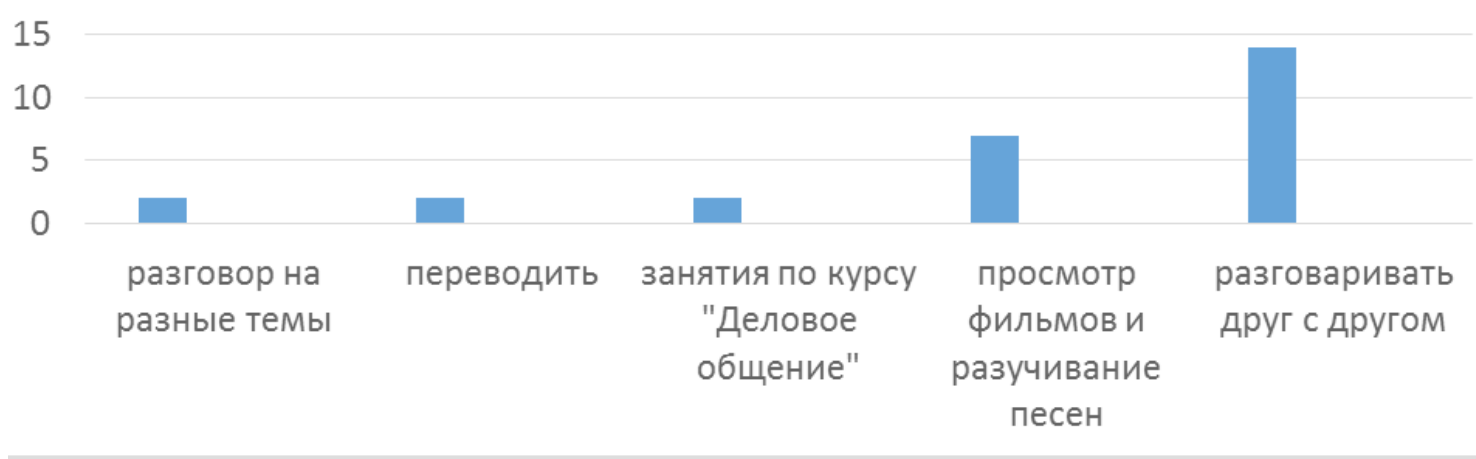

Наибольшее число студентов ответили, что они хотят больше разговаривать друг с другом, то есть студентам не хватает тех отведённых часов на занятиях по русскому языку, поскольку кроме устных опросов и ведения диалогов на занятиях предусмотрены виды работ по письму, аудированию, чтению. Наибольший процент часов, как правило, на младших курсах отводится изучению грамматики языка, на основе которой студенты могут правильно и грамотно изъясняться как в письменной, так и в устной речи. Следующая позиция студентов заключалась в том, что они желают проводить просмотры фильмов и разучивать песни на русском языке. В связи с этим нами было принято решение о создании дополнительных курсов по говорению, а именно организации кружка русского языка «Разговорный клуб русского языка», в котором студенты проводили вечера русской поэзии, смотрели фильмы, переводили занимательные тексты, занимались практикой языка. Координаторами этих курсов были студенты, имеющие продвинутый уровень языка, а приглашённые гости: студенты, преподаватели - носители языка - выступали в качестве жюри и экспертов.

Таким образом, пожелания студентов заключались в том, чтобы усилить работу и увеличить нагрузку по взаимодействию студентов друг с другом.

Ниже отражён анализ всех вопросов по наибольшему возрастанию процентных соотношений. Рассмотрим их более подробно. Так, 20 \% опрошенных студентов ответили, что русский язык они начали изучать ещё в средней школе; более 12 \% студентов считают, что изучение русского языка - это, прежде всего, требование, которое они должны выполнять; 12 \% опрошенных наиболее трудной частью грамматики русского языка назвали морфологию; 12 \% респондентов ответили, что категории рода и числа - самая лёгкая тема в изучении; вопрос о том, что легче всего даётся, показал такие результаты: около 30 \% студентов легче писать самостоятельно, чем под диктовку, 
более 20 \% - читать и пересказывать, 20 \% студентов предпочитают больше слушать и говорить; около 30 \% считают, что разговаривать друг с другом намного легче; 25 \% нравится говорить на социальные темы; 35 \% трудно переводить; более $45 \%$ студентов легче переводить с русского языка на родной; более $25 \%$ студентов считают, что использование родного языка благоприятно отразится на изучении языка; 14 \% опрошенных считают, что нужно больше разговаривать друг с другом Обобщённые сведения представлены в диаграмме 14.

Диаграмма 14

Обобщение

Diagram 14

Summarization

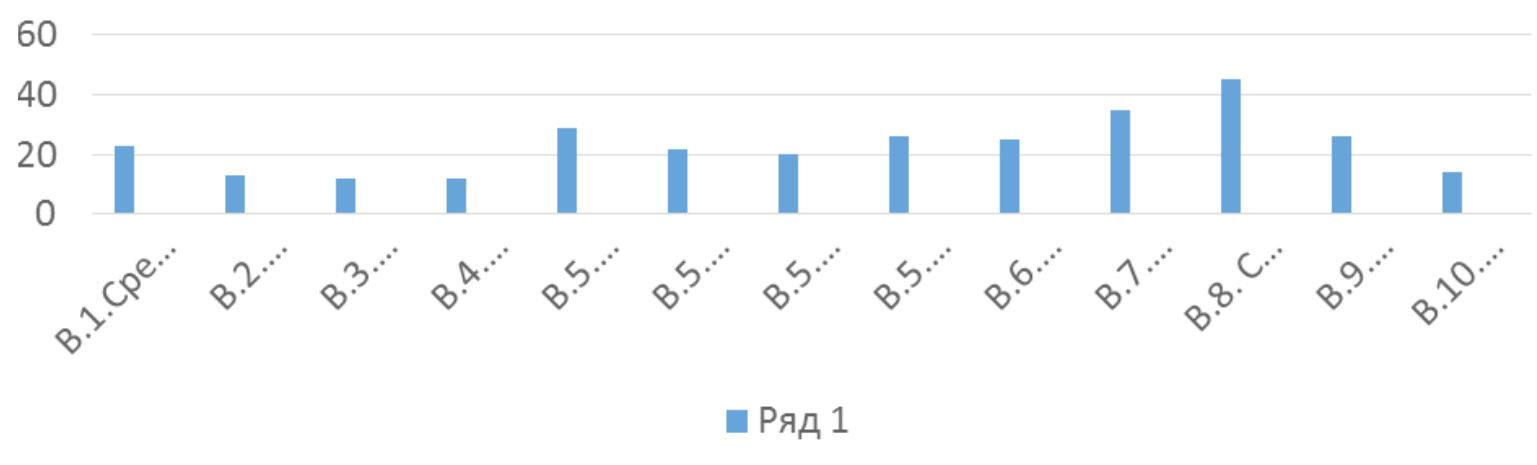

Таким образом, мы видим, что действительно существуют проблемы в изучении русского языка. Выявленные проблемы решаются в комплексе поставленных задач, а именно в практическом применении педагогических технологий, методов и приёмов, которые способствуют эффективному изучению иностранного языка. Несомненно, важную роль в данной стратегической концепции играет преподаватель, который является, по мнению И. И. Барахович, профессиональным коммуникатором, профессиональная деятельность которого «непосредственно связана с воздействием на партнёра, его мировоззрение, систему ценностей, его поведение и реализуется с помощью коммуникативных стратегий и тактик: прагматических, диалоговых, риторических» [2, с. 90].

На сегодняшний день существует потребность в повышении эффективности работников, мобилизации их внутреннего потенциала. В связи с этим коучинг становится одним из эффективных и популярных направлений во всем мире. Он направлен, прежде всего, на развитие человеческого потенциала, осознанность, активную жизненную позицию в решении личных, профессиональных и деловых задач, рефлексивность и осмысленность деятельности. Взаимодействие коуча происходит благодаря диалоговой, недирективной политике, субъект-субъектному характеру. Коучинговая подготовка принципиально отходит от традиционного обучения, ориентированного на знания, её ядром является обучение в деятельности, наставничество со стороны опытного коуча [5, с. 6]. Поэтому стратегия «профессиональный коммуникатор (преподаватель) - коуч (студент)» имеет положительную динамику, поскольку преподаватель будет коммуникативно воздействовать на студента и реализовывать свои интенции 
с помощью коммуникативных стратегий и тактик, а студент будет взаимодействовать с преподавателем в деятельностном обучении.

Итак, обобщим некоторые суждения. В процессе обобщения фактического материала круглого стола было выявлено, что недостаточная мотивированность в изучении иностранного языка, трудность в освоении грамматических тем, сложность профессионального тезауруса, работа с переводом и т. д. в отсутствии языковой среды изучаемого языка решаются с помощью достаточно традиционных, но весьма эффективных методов и технологий, применяемых в методике РКИ. Практические материалы диагностического исследования могут помочь преподавателям РКИ в разработке корректировочных курсов обучения РКИ для нефилологов.

Преподавателю как профессиональному коммуникатору рекомендуется использовать все возможные интерактивные, современные, эффективные технологии, методы и приёмы, которые построены на принципах прагматичности, преобразовательности, конвенциональности, обратной связи, критериальности для формирования у обучающихся коммуникативной компетентности. Таким образом, стратегическая концепция «профессиональный коммуникатор коуч», основанная на системно-деятельностном и практико-ориентированном подходах, имеет, на наш взгляд, перспективу развития.

\section{Автор прочитал и одобрил окончательнылй вариант рукописи.}

\section{Список литературы}

1. Базарова Т. С., Хинзеева Н. П. Формирование коммуникативной компетентности иностранных студентов в иноязычной образовательной среде : монография. Улан-Удэ : Изд-во Бурят. гос. ун-та, 2018. 190 с.

2. Барахович И. И. Форсайт образования: ценности, модели и технологии дидактической коммуникации XXI века. Коллективная монография/ под ред. М. Р. Арпентьевой и др. Канада, Торонто : Альтасфера, 2018. 710 с.

3. Бизнес-словарь. [Электронный ресурс]. URL: https://bakunin.com/coaching/ (дата обращения: 11.02.2020).

4. Карюкина О. А. Практико-ориентированный подход в подготовке специалистов [Электронный ресурс]. URL: https://nsportal.ru/npo-spo/obrazovanie-i-pedagogika/ library/2014/11/16/praktiko- orientirovannyy-podkhod-v-podgotovke (дата обращения 17.05.2020).

5. Кларин М. В. Профессиональный стандарт «Коуч»: развитие коучинга как профессии [Электронный ресурс] // Организационная психология. 2014. Т. 4. № 1. С. 6-16. URL: http://orgpsyjournal.hse.ru/ (дата обращения: 04.02.2020).

6. Козорог 3. П. Оптимизация процесса обучения русскому языку как иностранному [Электронный ресурс] // IX Международная научно-практическая конференция «Личность-слово-социум - 2008». URL: www.pws-conf.ru/nauchnaya/lss-2008/273pedagogika-visshei-shkoli.html (дата обращения: 11.02.2020).

7. Обязательно ли перевод должен выполняться на родной язык? [Электронный реcypc] // ALBA translating company. URL: https://www.alba-translating.ru/ru/ru/lang/nativespeaker.html (дата обращения: 11.02.2020).

8. Ожегов С. И., Шведова Н. Ю. Толковый словарь русского языка. [Электронный pecypc]. М. : Азь. 1992. URL: https://ozhegov.slovaronline.com/22215-PEREVOD (дата 
обращения: 11.02.2020).

9. Перевод как вид языкового посредничества. [Электронный ресурс] // Курс лекций по теории перевода / Е. Ю. Богатская, С. В. Невольникова. Ростов н/Д. : Издат. центр ДГТУ 2011. URL: https://studfile.net/preview/4001868/page:3/(дата обращения: 10.03.2020).

10. Тер-Минасова С. Г. Язык и межкультурная коммуникация. М. : Слово, 2000. $624 \mathrm{c}$.

\section{References}

1.Bazarova T.S., Khinzeeva N.P. Formirovaniye kommunikativnoi kompetentnosti inostrannikh studentov $\mathrm{v}$ inoyazychnoi obrazovatelinoi srede [Formation of communicative competence of foreign students in a foreign language educational environment]. Ulan-Ude, Buryat State University Publ., 2018, 190 p. (in Russian)

2. Barakhovich I. I. Forsite obrazovaniya: tsennosti, modeli i technologii didakticheskoi kommunikatsii XXI veka [Foresight of education: values, models and technologies of didactic communication of the 21 st century]. Kollektivnaya monografiya/ pod red. M. R. Arpent'evoj i dr. [Collective monograph/ ed. by M.R. Arpenieva, a.o.]. Toronto, Alitasphera Publishing and Literary Agency, 2018, 710 p. (in Russian)

3. Business Dictionary. Available at: https://bakunin.com/coaching/ (accessed: 11.02.2020) (in Russian)

4. Karyukina O. A. Praktiko-oriyentirovannyi podkhod v podgotovke spetsialistov [Practice-oriented approach to training of specialists]. Available at: https://nsportal.ru/npo-spo/ obrazovanie-i-pedagogika/library/2014/11/16/praktiko-orientirovannyy-podkhod-v-podgotovke (accessed: 17.05.2020) (in Russian)

5. Klarin M. V. Professionalnyi standart "Kouch": razvitiye kouchinga kak professii [Professional standard "Coach": the development of coaching as a profession]. Organizatsionnaya psikhologiya [Organizational psychology]. 2014, vol. 4, no. 1, pp. 6-16. Available at: http://orgpsyjournal.hse.ru/ (accessed: 04.02.2020) (in Russian)

6. Kozorog Z. P. Optimizatsiya protsessa obucheniya russkomu yazyku kak inostrannomu [Optimization of the process of teaching Russian as a foreign language]. IX Mezhdunarodnaya nauchno-prakticheskaya konferentsiya «Lichnost'-slovo-sotsium - 2008» [The 9th International Science and Practice Conference "Personality-Word-Society 2008"]. Available at: www.pws-conf.ru/nauchnaya/lss-2008/273-pedagogika-visshei-shkoli.html (accessed: 11.02.2020) (in Russian)

7. Obyazatel'no li perevod dolzhen vipolnyatsya na rodnoi yazyk? [Should the translation be carried out into the native language?]. Alba translating company. Available at: https:// www.alba-translating.ru/ru/ru/lang/native-speaker.html (accessed: 11.02.2020) (in Russian)

8. Bogatskaya E. Yu., Nevolinikova S. V. Perevod kak vid yazykovogo posrednichestva [Translation as a type of language mediation]. Kurs lektsij po teorii perevoda [Lectures on the theory of translation]. Rostov on Don: DGTU Publ., 2011. Available at: https://studfile. net/preview/4001868/page:3/ (accessed: 10.03.2020) (in Russian)

9. Ter-Minasova S.G. Yazyk i mezhkuliturnaya kommunikatsiya [Language and intercultural communication]. Moscow: Slovo Publ., 2000, 624 p. (in Russian)

10. Ozhegov S.I., Shvedova N. Yu. Tolkovy slovar' russkogo yazyka [Explanatory dictionary of the Russian language]. Moscow: Az' Publ., 1992. Available at: https://ozhegov. slovaronline.com/22215-PEREVOD (accessed: 11.02.2020) (in Russian) 


\title{
A Diagnostic Survey of Mongolian Students for Solving Problems of Teaching Russian as a Foreign Language in a Foreign Educational Environment
}

\author{
Natalya P. Khinzeeva \\ Ulaanbaatar Branch of Plekhanov Russian University of Economics, \\ Mongolia, Ulaanbaatar
}

\begin{abstract}
Introduction. The focus of the paper is on teaching and studying Russian as a foreign language. The research aims to identify and analyze the problems in teaching Russian as a foreign language, examine the reasons that impede adequate language acquisition, and highlight the main factors contributing to the effective teaching of Russian as a foreign language.
\end{abstract}

Materials and Methods. The research involved summarizing the factual information, which helped reveal its scientific novelty that lies in the introduction of coaching technologies in the teaching methodology of Russian as a foreign language. The implementation of this technology is associated with system-activity and practice-oriented approaches to the teaching of students. The theoretical significance of the research lies in the determination of the strategic concept "professional communicator (teacher) - coach (student)". This concept suggests that the activity of communicator impact on the partner (their worldview, value system, and behavior) and relies on communicative strategies and tactics (pragmatic, dialogue-based, and rhetorical). The coach interaction, however, is subject-subject in nature and is based on the dialogue, non-directive policy.

Results of the study. The findings of the research are of theoretical and practical significance for improving the teaching methods of Russian as a foreign language. The paper presents recommendations to solve the problems raised, and concludes that system-activity and practice-oriented approaches should work in a complex and be among the predominant in training.

Conclusion. The focus on improving the communicative competence of foreign students frames the practical importance of the research. The need to increase communicative competence in foreign students determines the viability of this area in science. Further research is required to investigate new methods and forms of teaching Russian as a foreign language.

Keywords: problems in the study of Russian as a foreign language, systemactivity and practice-oriented approaches, professional communicator, coach, communicative interaction. 


\section{Педагогический ИМИДЖ}

\section{Хинзеева Наталья Петровна}

кандидат педагогических наук, старший преподаватель

ORCID https://orcid.org/00000003-0309-6549

Улан-Баторский филиал Российского экономического университета им. Г. В. Плеханова

210351, Монголия, г. Улан-Батор, район Баянзурх, проспект Мира, 131.

тел.: +976(11)450596

e-mail:nadulai777@mail.ru

\section{Khinzeeva Natalya Petrovna}

Candidate of Sciences (Pedagogy), Senior Lecturer

ORCID https://orcid.org/00000003-0309-6549

Ulaanbaatar Branch of Plekhanov Russian University of Economics

131 Peace St, Bayanzurkh District, Ulaanbaatar, Mongolia, 210351

tel.: +976(11)450596

e-mail:nadulai777@mail.ru 